\title{
Effects of low pH on synthesis and release of catecholamines in the cat carotid body in vitro
}

\author{
R. RIGUAL ${ }^{1}$, E. GONZALEZ ${ }^{1}$, S. FIDONE ${ }^{2}$ and C. GONZALEZ 1 \\ ${ }^{1}$ Departamento de Fisiología y Bioquímica, Facultad de Medicina, Valladolid (Spain) and ${ }^{2}$ Department of of Physiology, \\ School of Medicine, University of Utah, Salt Lake City, UT (U.S.A.)
}

(Accepted May 1st, 1984)

Key words: carotid body — dopamine - noradrenaline — synthesis - release - acidosis

\begin{abstract}
The rates of dopamine and noradrenaline synthesis in the cat carotid body (c.b.) are $5.9 \pm 0.58 \mathrm{pmol} / \mathrm{c} . \mathrm{b} . / 2 \mathrm{~h}$ and $0.3 \pm 0.02$ pmol/c.b. $/ 2 \mathrm{~h}$, respectively. The synthesis is doubled when the organs are incubated at $\mathrm{pH} 7$. Similarly, low pH induces a release of dopamine from the c.b. which is proportional to increased activity in the carotid sinus nerve.
\end{abstract}

The carotid body (c.b.) is a chemoreceptor organ activated by environmental low $\mathrm{pO}_{2}$, low $\mathrm{pH}$ and high $\mathrm{pCO}_{2}$. It possesses clusters of cells of two different types, type I (glomus) and type II (sustentacular) cells. Sensory nerve fibers penetrate into the clusters and their endings form synaptic-like contacts with type I cells. Type I cells possess dense core vesicles in their cytoplasm which contain catecholamines (CA). The possible role of $\mathrm{CA}$ as neuroregulators between type I cells and sensory endings is a matter of dispute because the most abundant $\mathrm{CA}$ in the c.b., dopamine (DA), behaves as an excitatory or inhibitory agent depending on the dose employed ${ }^{21}$ or the animal species used ${ }^{16}$. Further, a decrease in CA content (an index of CA release) after hypoxic stimulation has not always been observed (see ref. 6 for a review). In a very recent article by Fitzgerald et al. ${ }^{10}$, the effect of severe hypercapnic acidosis has been studied in the cat c.b. and no decrease in CA content was observed; similar findings have been reported for the rat c.b. ${ }^{13}$.

In recent years ${ }^{7-9}$ we have used an in vitro preparation 5 to measure $\mathrm{CA}$ release and have reported that hypoxia releases DA from rabbit and cat c.b.s parallel to the increased electrical activity in the carotid sinus nerve (c.s.n.). In the present report we show, with the same preparation, that low $\mathrm{pH}$ enhances the rate of both DA and NE synthesis and that this stimulus also elicits an increase in DA release concomitant with the increased activity of the c.s.n.

Cats were anesthetized with sodium pentobarbitone $(30-40 \mathrm{mg} / \mathrm{kg}$ i.p.) and artificially respired while the carotid area was exposed. To study the synthesis of CA, the carotid bifurcation was removed and placed in a lucite chamber filled with ice-cold $100 \% \mathrm{O}_{2}$ equilibrated Tyrode $^{2}$ (in mmol: $\mathrm{NaCl}, 112$; $\mathrm{KCl}, 4.7 ; \mathrm{CaCl}_{2}, 2.2 ; \mathrm{MgCl}_{2}, 1.1$; sodium glutamate, 42; Hepes, 5; glucose 5.6, adjusted to $\mathrm{pH}=7.4$ with $1 \mathrm{~N} \mathrm{NaOH}$ ). The c.b.s. were dissected out, thoroughly cleaned of surrounding connective tissue and incubated at $37^{\circ} \mathrm{C}$ for $2 \mathrm{~h}$ in small vials placed in a metabolic shaker. The incubation medium $(0.5 \mathrm{ml})$ was $100 \% \mathrm{O}_{2}$-equilibrated Tyrode containing $10^{-4} \mathrm{M}$ 6- $\mathrm{MPH}_{4}$ (Sigma) and $40 \mu \mathrm{M} \mathrm{3,5}\left[{ }^{3} \mathrm{H}\right]$ tyrosine (spec. act. $2 \mathrm{Ci} / \mathrm{mmol}$, Amersham). The final $\mathrm{pH}$ of the media was 7.4 (control) and 7.0 (experimental). At the end of incubation, the organs were homogenized and the supernatants processed for TLC as described by Fleming and Clark ${ }^{12}$, except that the plates were stained with potassium ferricyanide to minimize quenching. In some experiments the incubation media were passed through alumina and all the catechol compounds eluted with $1 \mathrm{~N} \mathrm{HCl}$; the eluates were dried in a vacuum concentrator (Savant) and resuspended in $40 \mu 1$ of the solvent used for TLC and chro-

Correspondence: C. Gonzalez, Departamento de Fisiología y Bioquímica, Facultad de Medicina, Valladolid, Spain. 
TABLE I

Effects of low pH on $\left[{ }^{3} H\right] C A-s y n t h e s i s$ in the c. $b$.

The data (pmol/c.b.) are means \pm S.E. of 8 pairs of c.b. Difference was tested by the paired $t$-test.

\begin{tabular}{llrl}
\hline & $p H=7.4$ & \multicolumn{1}{c}{$p H=7$} & $P$ \\
\hline$\left[{ }^{3} \mathrm{H}\right]$ Tyrosine & $7.2 \pm 0.95$ & $6.5 \pm 0.60$ & n.s. \\
{$\left[{ }^{3} \mathrm{H}\right] \mathrm{NE}$} & $0.3 \pm 0.02$ & $0.7 \pm 0.08$ & 0.005 \\
{$\left[{ }^{3} \mathrm{H}\right] \mathrm{DA}$} & $5.9 \pm 0.58$ & $12.5 \pm 2.50$ & 0.02 \\
\hline
\end{tabular}

matographed.

To study the release of DA and the sensory nerve discharge, the cleaned c.b.s and their own carotid sinus nerves (c.s.n.) were incubated as before $\left(\mathrm{pH}=7.4\right.$ ) with $\left[{ }^{3} \mathrm{H}\right]$ tyrosine of high specific activity $(20 \mathrm{Ci} / \mathrm{mmol})$. At the end of incubation they were mounted in a superfusion chamber as described elsewhere 8.9 . The action potentials from the c.s.n. were led through an AC-coupled preamplifier to an oscilloscope. The amplified signals were also led through a window discriminator to a digital counterprinter which read the total number of nerve impulses recorded during a collection period. The superfusates were collected in vials containing a carrier solution ( $0.3 \mathrm{M}$ acetic acid, $1 \mathrm{mM}$ ascorbic acid) and processed with alumina to adsorb the labeled catechol compounds $\left(\left[{ }^{3} \mathrm{H}\right] \mathrm{DA}\right.$ and $\left.\left[{ }^{3} \mathrm{H}\right] \mathrm{DOPAC}\right)$ which were eluted with $1 \mathrm{~N} \mathrm{HCl}^{20}$ and measured by liquid scintillation counting. In some experiments the alumina eluates were dried in a vacuum concentrator, resuspended and further analyzed by TLC to verify the identity of the radioactive compounds.

Lowering the $\mathrm{pH}$ of the incubation media from 7.4 to 7 , produced a significant increase in $\left[{ }^{3} \mathrm{H}\right] \mathrm{NE}$ and $\left[{ }^{3} \mathrm{H}\right] D A$ content without any significant change in free $\left[{ }^{3} \mathrm{H}\right]$ tyrosine content (Table I). The only $\left[{ }^{3} \mathrm{H}\right]$ catechol measurable in the incubation media was [ $\left.{ }^{3} \mathrm{H}\right] \mathrm{DOPAC}$, in amounts representing about $25 \%$ of the $\left[{ }^{3} \mathrm{H}\right] \mathrm{DA}$ present in the c.b.s of each group.

The release of $\left[{ }^{3} \mathrm{H}\right] \mathrm{DA}$ (measured as $\left[{ }^{3} \mathrm{H}\right] \mathrm{DA}+$ $\left[{ }^{3} \mathrm{H}\right] \mathrm{DOPAC}$ ) was dependent on the $\mathrm{pH}$ of the superfusion media. Fig. 1 shows the time-course of low $\mathrm{pH}$-induced release of DA from type I cells and activity in the c.s.n. in a single experiment. The proportionality between both parameters is evident in Fig. 2 which summarizes the results of $6-8$ experiments.
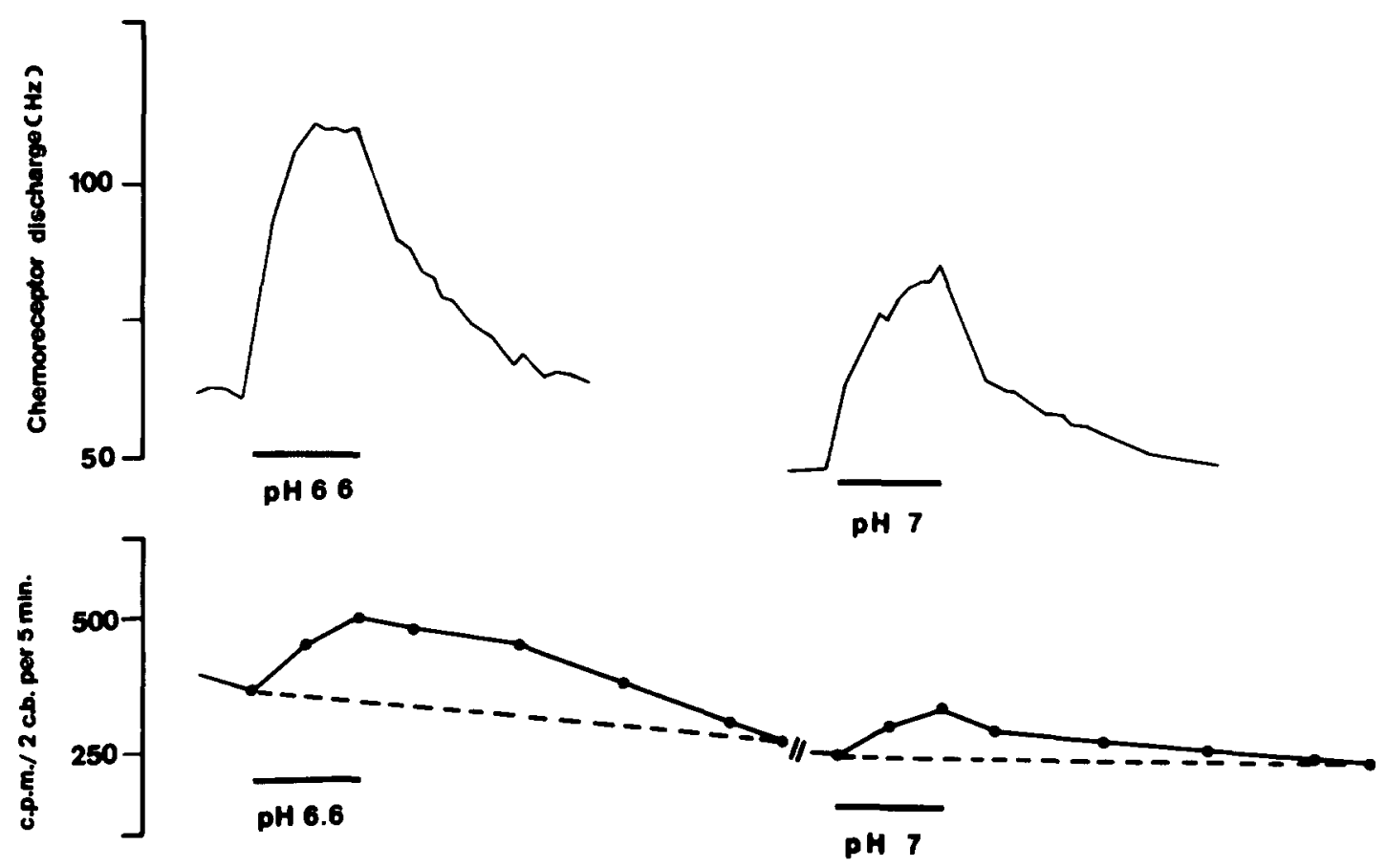

Fig. 1. Both c.b.s from one cat previously loaded with $\left[{ }^{3} \mathrm{H}\right] \mathrm{DA}$ were placed in the superfusion chamber and the electrical activity of the c.s.n. of one of them was continuously monitored. Superfusates were collected every 5 or $10 \mathrm{~min}$. The top of the figure shows the change in c.s.n. activity induced by $10 \mathrm{~min}$ of superfusion at low $\mathrm{pH}$. The lower part shows the change in $\left[{ }^{3} \mathrm{H}\right] \mathrm{DA}$ release $(\mathrm{measured}$ as $\left.\left[{ }^{3} \mathrm{H}\right] \mathrm{DA}+\left[{ }^{3} \mathrm{H}\right] \mathrm{DOPAC}\right)$ induced by the same experimental maneuver. 


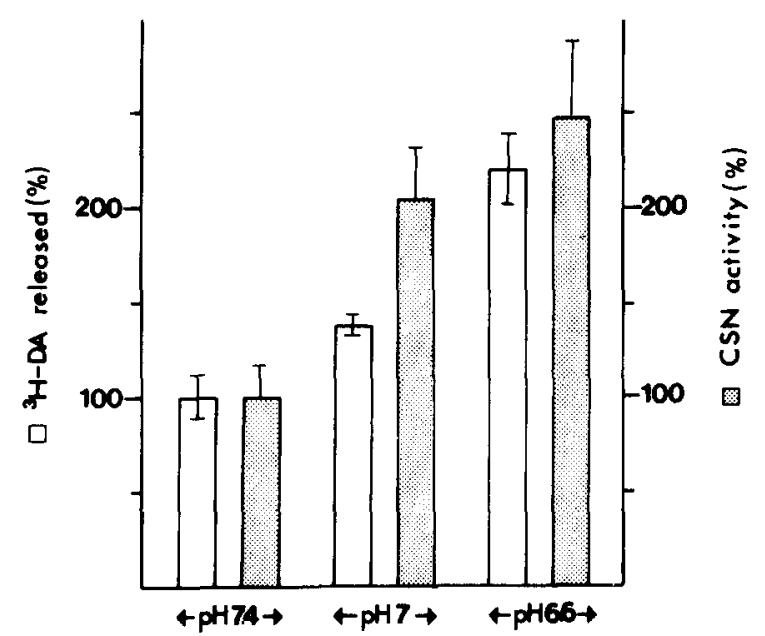

Fig. 2. Means \pm S.E. of the c.s.n. activity and release of [ $\left.{ }^{3} \mathrm{H}\right] \mathrm{DA}$ at 3 different $\mathrm{pHs}$ obtained in $6-8$ experiments. Results are expressed as \% of that obtained at $\mathrm{pH} 7.4(100 \%)$.

Our results clearly show that the rate of synthesis and release of DA by the c.b. increases when the extracellular $\mathrm{pH}$ is reduced; there is a parallelism between the $\mathrm{pH}$-induced release of DA from type I cells and the $\mathrm{pH}$ induced activity in the c.s.n. which suggests a possible linkage between both events.

The stimulatory effect of low $\mathrm{pH}$ on CA synthesis in the c.b. conforms to findings in other structures $1,3,15,18$. In agreement with the results obtained in synaptosomes ${ }^{18}$, our data suggest that the increased hydrogen ion concentration modifies the kinetic parameters of tyrosine hydroxylase in the c.b. In addition, our direct measurement of the rate of CA synthesis in the c.b. explains the findings of Hanbauer ${ }^{13}$, who reported an increase in CA content in the rat c.b. after exposure of the animals to a hypercapnic atmosphere.

The release of DA by the c.b. is very sensitive to extracellular $\mathrm{pH}$ when compared to other structures; for example, according to Cantu et al..$^{4}$, the output of

\section{REFERENCES}

1 Almaraz, L., Rigual, R., Obeso, A. and Gonzalez, C., Síntesis de catecolaminas y TRIS buffer, FESBE-2 (Abts), (1981) 306.

2 Barón, M. and Eyzaguirre, C., Effects of temperature on some membrane characteristics of carotid body cells, Amer. J. Physiol., 233 (Cell Physiol. 2) (1977) C35-C46.

3 Boarder, M. R. and Fillenz, M., Synaptosomal tyrosine hy-
CA from the dog adrenal medulla increases only when $\mathrm{pH}$ drops to 6.85-6.95 and according to other authors ${ }^{17}$, $\mathrm{pH}$ must drop below 6.8 to detect an increase in adrenal medullary secretion. In striatal slices a $\mathrm{pH}$ of 6.5 did not produce any significant increase in DA release ${ }^{19}$.

It was reported in a recent publication ${ }^{10}$ that hypoxia releases DA in the cat $c . b$. in vivo whereas hypercapnic acidosis does not. It was concluded that the process of chemosensory activation induced by these stimuli must be different. However, it should be noted that even intense hypercapnic acidosis produces only a modest increase in c.s.n. activity when compared with hypoxia ${ }^{11}$. Therefore, if the proportionality between DA release and c.s.n. activity seen with hypoxia ${ }^{7,8,9}$ holds for acidosis, it should be difficult to detect changes in DA content in the c.b. induced by acidosis.

As shown in this paper there is also a parallelism between acidosis-induced release of DA and activity in the c.s.n., suggesting that acidosis, like hypoxia, acts via type I cells. However, when the data obtained with acidosis are compared with those for hypoxia ${ }^{9}$ it appears that for a given level of activity in the c.s.n. the release of DA is higher with hypoxia; this seems to imply either that acidosis also directly activates the sensory nerve endings, as seen in other structures ${ }^{14}$, or that acidosis makes the c.s.n. endings more sensitive to the neuroregulators released from type I cells. As a whole, the data show that type I cells detect the natural stimulus of acidosis and that DA seems to play an important role in the generation of chemoreceptor impulses.

We thank Professors C. Eyzaguirre, B. Herreros and R. Fitzgerald for their criticisms during the preparation of the manuscript. The work was supported by a grant from the C.A.I.C.T. of Spain and by a USPHS Grant NS-12636.

droxylation in the rat brain: comparison of activity from hippocampus and hypothalamus with activity from striatum, J. Neurochem., 31 (1978) 1419-1426.

4 Cantu, R. C., Nahas, G. G. and Manger, W. M., Effect of hypercapnic acidosis and of hypoxia on adrenal catecholamine output of the spinal dog, Proc. Soc. exp. Biol. (N.Y.), 122 (1966) 434-437.

5 Eyzaguirre, C. and Lewin, J., Effect of different oxygen tensions of the carotid body in vitro, J. Physiol. (Lond.), 
159 (1961) 238-250.

6 Fidone, S. and Gonzalez, C., Peripheral chemoreceptors: initiation and control of discharge. In N. Cherniak and J. G. Widdicombe (Eds.), Handbook of Physiology, Vol. I (1984) in press.

7 Fidone, S., Gonzalez, C. and Yoshizaki, K., Synthesis and release of catecholamines by the cat carotid body. Effect of hypoxic stimulation, Neurosci. Abstr., 5 (1979) 402.

8 Fidone, S., Gonzalez, C. and Yoshizaki, K., A study of the relationship between dopamine release and chemosensory discharge from the rabbit carotid body in vitro: preliminary findings. In C. Belmonte, D. Pallot, H. Acker and S. Fidone (Eds.), Arterial Chemoreceptors - Proc. VIth Int. Meeting, Leicester, Leicester Univ. Press. (1981) 209-219.

9 Fidone, S., Gonzalez, C. and Yoshizaki, K., Effects of low oxygen on the release of dopamine from the rabbit carotid body in vitro, J. Physiol. (Lond.), 333 (1982) 93-110.

10 Fitzgerald, R. S., Garger, P., Hauer, M. C., Raff, H. and Fechter, L., Effect of hypoxia and hypercapnica on catecholamine content in cat carotid body, J. appl. Physiol.: Respirat. Environ. Exercise Physiol., 54 (5) (1983) 1408-1413.

11 Fitzgerald, R. S. and Parks, D. C., Effect of hypoxia on carotid chemoreceptor response to carbon dioxide in cats, Respirat. Physiol., 12 (1971) 218-229.

12 Fleming, R. M. and Clark, W. G., Quantitative thin-layer chromatographic estimation of labelled dopamine and norepinephrine, their precursors and metabolites, J. Chromatogr., 52 (1970) 305-312.

13 Hanbauer, I., Role of catecholamines in the function of rat carotid body, Proc. Internat. Union Physiol. Sci., v., XIV (1980) 133.

14 Krishtal, O. A. and Pidoplichko, V. I., Receptor for protons in the membrane of sensory neurons, Brain Research, 214 (1981) 150-154.

15 Kuczenski, R. and Segal, D. S., Intrasynaptosomal conversion of tyrosine to dopamine as an index of brain catecholamine biosynthesic capacity, J. Neurochem., 22 (1974) 1039-1044.

16 Monti-Bloch, L. and Eyzaguirre, C., A comparative physiological and pharmacological study of cat and rabbit carotid body chemoreceptors, Brain Research, 193 (1980) 449-470.

17 Morris, M. E. and Millar, R. A., Blood pH/plasma catecholamine relationships: respiratory acidosis, Brit. $J$. Anaesth., 34 (1962) 672-681.

18 Patrick, R. L. and Rendel, M. T., pH-induced alterations in dopamine synthesis regulation in rat brain striatal synaptosomes, J. Neurochem., 34 (6) (1980) 1506-1513.

19 Schwarz, R. D., Uretski, N. J. and Bianchine, J. R., The relationship between the stimulation of dopamine synthesis and release produced by amphetamine and high potassium in striatal slices, J. Neurochem., 35 (5) (1980) 1120-1127.

20 Weil-Malherbe, H., Determination of catecholamines. In D. Glick (Ed.), Methods of Biochemical Analysis: Analysis of Biogenic Amines and their Related Enzymes, Interscience Publishers, New York, (1971) 119-152.

21 Zapata, P., Effects of dopamine on carotid chemo and baroreceptors in vitro, J. Physiol. (Lond.), 244 (1975) $235-251$. 